\title{
Ontology and Metaontology A Contemporary Guide
}

Francesco Berto and Matteo Plebani 


\section{Table of Contents}

Acknowledgements ix

Introduction: What Is Ontology? What Is

Metaontology? 1

Part I Quinean Metaontology

1 On Denoting 15

2 1948: On What There Is 23

3 The Standard View 34

Part II Alternative Metaontologies

4 Ontological Pluralism and Neo-Fregeanism 55

5 Carnap's View of Ontology and Neo-Carnapians 68

6 Fictionalism 83

7 Meinongianism 99

8 The Grounding Approach 113

Part III Ontology

9 Abstract Objects I: Numbers \& Co. 123

10 Abstract Objects II: Linguistic Types, Propositions and Values 152 
viii Contents

11 Possible Worlds 163

12 Material Objects 181

13 Fictional Objects 199

14 Beyond Particulars: Properties and Events 211

References 229

Index 241 


\section{Acknowledgements}

We are most grateful to Doug Edwards, David Liggins, Tuomas Tahko, Stephan Torre, Achille Varzi and Alberto Voltolini for their helpful comments and remarks on various parts of this book. The division of labour for it has been as follows: we wrote the Introduction together. Chapters 1, 3, 7, 8, 11, 12 and 13 were written by Francesco Berto. Chapters 2, 4, 5, 6, 9, 10 and 14 were written by Matteo Plebani. We reviewed each other's chapters.

Parts of Chapters 1, 3, and 7 draw on Chapters 2 and 4-6 of Francesco Berto's Synthèse Library book Existence as a Real Property. Thanks to Springer for allowing us to use that material.

Parts of Chapter 9 draw on Matteo Plebani's survey of nominalistic strategies in the philosophy of mathematics ('Nominalismo in filosofia della matematica') for the online journal Aphex. Thanks to the editors for allowing us to use that material.

Parts of Chapter 11 come from Francesco Berto's entry 'Impossible Worlds' for the Stanford Encyclopedia of Philosophy. Thanks to the editors, and particularly to Ed Zalta, for allowing us to reuse that material. 



\section{Introduction: What Is Ontology? What Is Metaontology?}

\section{Chapter Outline}

1 Ontology ...

2 ... And metaontology 2

3 ... And metaphysics 3

4 ... And science, and common sense 5

5 The rest of the book 9

\section{Ontology ...}

Biology studies living things. Psychology studies mental functions. Astronomy deals with celestial phenomena and mathematics deals with numbers. They all study something, of course, but none of them studies everything. They do not address the whole of reality, or all that there is. Ontology does.

This characterization of ontology can be traced back to Aristotle, who in Book Four of his Metaphysics introduced the idea of a 'science of being qua being', or of being as such. Yet Aristotle did not use (a Greek counterpart of) the word 'ontology' to name such a science, although the term comes from ón, the present participle of einai, the Greek verb for 'to be'. The word is a more recent seventeenth-century coinage (nor did Aristotle use a Greek counterpart of the word 'metaphysics' - we will get back to this). After having been dismissed by much early analytic and neopositivistic philosophy, ontology made an impressive comeback in the second half of the twentieth century. One initiator of the renaissance was Willard van Orman Quine, who made mainstream the idea that the task of ontology is to write down something like a complete catalogue of the furniture of the world. What we want from ontology is a list of all there is, and ontology gets the list right insofar as it misses nothing that is there, and includes nothing that isn't there.

However, many still think that there is something perplexing about the study of what there is, which sets it apart from the other above-mentioned disciplines. Laymen have a rough understanding of what biology, psychology or mathematics are about, and few doubt that living creatures, or the functioning of the mind or the realm of 
numbers, are legitimate areas of rational investigation. But, first, what does it mean to study being qua being, or what is? And, secondly, via which methods or procedures of inquiry should such a study be carried out? While there are many excellent introductions to ontology on the market, few deal extensively with these two issues - questions to which professional philosophers give conflicting answers. This provided our motivation for writing the book.

\section{2 ... And metaontology}

As its title makes explicit, this book is an introduction to ontology as well as an introduction to metaontology. And the term 'metaontology' is a very recent coinage: as far as we know, it officially entered the philosophical landscape as the title of a 1998 essay by Peter van Inwagen, one of the greatest contemporary ontologists. Now, van Inwagen understood metaontology as dealing precisely with the two issues just mentioned: if the key question for ontology, as Quine told us, is 'What is there?', then the (twofold) key question for metaontology is 'What do we mean when we ask "What is there?", and 'What is the correct methodology of ontology?'. By using the prefix 'meta-', van Inwagen meant to suggest a kind of higher level reflection: 'meta-X' as the inquiry on the central concepts and procedures of discipline $\mathrm{X}$.

It is only natural that the reflection on the proper methodology of a discipline historically comes after the discipline itself has flourished and developed its own conceptual tools. Perhaps the main element of novelty in early twenty-first-century ontological research is that many of its practitioners pay more and more attention to metaontological issues. 'Metaontology', as Ross Cameron 2008: 1 said, 'is the new black. This book aims to give a textbook presentation of the discipline in line with such recent developments.

Now the metaontological turn has brought a rediscovery of some traditional and pre-Quinean approaches to ontology. As for the first of those two meta-questions, 'What do we mean when we ask "What is there?": the catalogue metaphor embedded in the Quinean view has it that the goal of ontology is to write a list of everything that falls under the notion being. But the original Aristotelian idea of a 'science of being qua being' was concerned, first of all, with the very concept of being, that is, with the meaning of the notion itself. Quine did have something important to say on the meaning of being, as we will see in the first part of the book. Other recently developed metaontological stances differ from the Quinean approach in their conceptualization of being as such, and from this they derive different views of ontology's tasks. Some say that the primary goal of ontology is not to write a list of all there is, but (as also Aristotle set out to do in the Metaphysics) to identify the most fundamental or basic entities: those which ground all the rest, and on which everything (else) depends. 
Some claim, as Aristotle himself did, that being can mean different things - that there are different ways of being - and that the primary goal of ontology is to identify these meanings, or ways of being. Some even introduce a distinction between being and what is there, and claim that some things should be included in the universal catalogue because they are there, although they lack being.

As for the second meta-question, namely 'What is the correct methodology of ontology?', the new methodological consciousness of twenty-first-century ontology has revitalized deflationist perspectives on the goals and ambitions of ontology itself. Quine's methodology for ontology was naturalistic: he believed that we should include in the universal catalogue the kinds of entities our best natural science commits us to (he also had views on how such 'ontological commitment' ought to be understood, as we will see). He thus denied that ontology has a special philosophical autonomy, allowing it to float freely from the findings of natural sciences. Contrary to the beliefs of his master Rudolf Carnap, Quine believed ontological questions to generally make perfect sense and to admit of substantive replies. Nonetheless, other philosophers nowadays are much more Carnapian: they think that ontological questions make sense only when appropriately restricted or qualified. Some have a more strongly dismissive approach, and believe that most such questions are just shallow: they reduce - as some founding fathers of analytic philosophy also thought - to confusions concerning the meanings of some expressions of our everyday language.

\section{3 ... And metaphysics}

Ontology entertains a complicated relationship with metaphysics, which is itself one of the most traditional parts of philosophy. The border between ontology and metaphysics in the works of contemporary philosophers is fuzzy. Some just use the two terms interchangeably. Sometimes the relationship between metaphysics and ontology is understood as of one between a discipline and one of its sub-disciplines.

As a first approximation, metaphysics is the branch of philosophy which asks what reality is like - as opposed to such other branches as epistemology, which asks what we can know about reality and how; or ethics, which asks how reality ought to be. Textbook presentations often say that metaphysics is an investigation into the most fundamental and general structures and features of reality (Crane and Farkas 2004; Garrett 2006).

Just as the word 'ontology', so the word 'metaphysics' comes onstage later than the Greek philosophers who can be considered the founding fathers of the discipline. It has a tangled history too. When Aristotle's works were ordered after his death, some of them were put after his writings on physics. They belonged to a discipline Aristotle 
called 'first philosophy', and which dealt with such fundamental topics as being, causation, God and other issues. Such writings then got the label of 'what comes after the books on physics', in Greek: tà metà tà physikà - hence, 'metaphysics'. Physics was taken as the study of the material world, subject to change, movement, generation and corruption. 'First philosophy', as the discipline that studies the most general and fundamental aspects of reality, was believed by Aristotle to transcend physics in some sense. In order to fully understand the foundations of reality, for him and for many others after him, one has to resort to incorporeal, nonphysical entities, such as God. So the name 'metaphysics' also came to mean a study that goes 'beyond physics' in this sense: it deals with a realm that surpasses, or is anyway not reducible to, the physical world.

Now when ontology is understood the Quinean way, that is as the quest for a catalogue of all there is, it may then be seen as in some sense a preliminary to metaphysics. One first writes down the complete inventory of reality - one says what is there. Then one wonders about the nature, structure and fundamental features of the kinds of things listed in the inventory.

Even if one agrees with the view of ontology as preliminary to metaphysics, the border between the two remains fuzzy: as we will experience throughout this book, ontological issues (so understood) naturally tend to shade into metaphysical ones (so understood). Thinking about the relationship between ontology and metaphysics in the aforementioned terms can help to understand the following pattern, often recurring in contemporary philosophy: authors A and B can seriously disagree on the metaphysical status of entities of kind $F$, which they nevertheless agree to include in the ontological catalogue. Here's one example that we will delve into in the third part of the book. The notion of possible world is extremely useful in most branches of contemporary philosophy. One starts by taking 'possible world' to stand for a way reality as a whole could be or could have been. This quickly leads to the natural twofold question: are there really possible worlds distinct from the actual one - that is should we include them in the ontological catalogue? And if so, then what kind of entities are they? Now philosophers A and B can agree on including possible worlds in their ontologies: they both reply 'yes' to the first ontological question. However A thinks that these things (possible worlds) are just like our actual world, but causally and spatiotemporally isolated from it. In particular they are, as we may say, (mostly) concrete material objects: things endowed with a mass, which occupy some space and are subject to the flow of time. On the contrary, B thinks of them as abstract objects things more similar to numbers, functions and, perhaps, concepts, than to these physical surroundings of ours. So A and B have diverging metaphysical views on possible worlds.

It is fair to say that such characterization of the relation between ontology and metaphysics, despite being widespread, is not uncontroversial. To begin with, it is possible to accept the ontology-as-catalogue metaphor without taking ontology to be 
preliminary to metaphysics. If one thinks of metaphysics as an attempt at 'writing the book of the world' (Sider 2011), then the ontological job will look like writing the index of contents to the book of the world. And the index of contents is often written when the book is close to completion. Some authors, for example, Bergmann 1967 and Grossmann 1992, believe that we just cannot decide whether some putative kind of entities should be included in the ontological catalogue without first giving some characterization of what the kind is like. These philosophers will tend to understand 'ontology' itself as meaning the study of the fundamental and most general structures of reality. They will then tend to use 'ontology' just as a synonym of 'metaphysics', or to blur any distinction between the two (for a comparison between this way of understanding ontology and the one followed by us above, see the introduction to van Inwagen 2001). Besides, the development of non-Quinean metaontologies, as we will see, has brought even more pressure on the mainstream way of drawing the line: for it presupposes the 'Quinean catalogue' view of ontology, which is questioned in some alternative metaontological approaches. This quick overview should make clear that this book, dealing with ontology and its methods, is perforce also, to some extent, a metaphysical book.

\section{4 ... And science, and common sense}

Let us stick again with the 'catalogue' or 'index of contents' metaphor for ontology. Another natural preliminary question about writing the catalogue or index of contents to the book of the world is: what is specifically philosophical - as opposed to scientific, on the one hand, and plainly commonsensical, on the other - about this task?

Sciences such as physics, chemistry, astronomy, biology, etc., already teach us a lot about the makeup of reality. We can learn, for instance, that the surface area of Saturn, measured in square kilometres, is $1.08 \cdot 10^{12}$ (Liggins 2008a), that some biological species are cross fertile, that spiders share some important anatomical features with insects (van Inwagen 2004), that the event of a solar flare can release several billions of joules of energy. Also, we share commonsensical knowledge on lots of things constituting the furniture of the world. We know that fragility is a feature of crystal glasses, that bananas are yellow when ripe, that a bikini is composed of a bra and a slip, that Emmental cheese has holes in it and that the Clinton-Lewinsky affair was a scandalous incident. Suppose we look at examples such as these and start writing down the following list:

1 Planets, like Saturn

2 Insects

3 Bananas 
4 Spiders

5 Bikinis

6 Holes, for example, in pieces of cheese

7 Numbers, like $1.08 \cdot 10^{12}$

8 Properties, such as fragility, ripeness, and genetic features

9 Biological species

10 Events, like solar flares and the Clinton-Lewinsky affair

11 ...

Would a list of this kind tell us an ontologically satisfying story? One problem is that it seems randomly constructed. It resembles the classification of animals in Borges' The Analytical Language of John Wilkins:

Those that belong to the Emperor

Embalmed ones

Those that are trained

Suckling pigs

Mermaids

Fabulous ones

Stray dogs

Those included in the present classification

Those that tremble as if they were mad

Innumerable ones

Those drawn with a very fine camelhair brush

Others

Those that have just broken a flower-vase

Those that from a long way off look like flies

One would like to impose more order and structure to our inventory of the furniture of the world: we want our list to be systematic, in some sense.

A related issue may be one of insufficient generality - though pinning down the exact level of generality is no easy task. Ontological catalogues don't typically stick with such entries as bikini, insect or banana, but comprise much more general categories. For instance, we may group planets like Saturn as well as insects, bananas, bikinis and human beings like Clinton and Lewinsky into a single very broad category. All things belonging to these kinds are, to retrieve a label we used above, concrete material objects: they all have mass, they occupy a place in the physical world.

But what about the sixth item in the list? Should we include holes in our catalogue of all there is? Holes being devoid of mass, they look quite unlike things belonging to the first five items. Is a hole something like an absence of matter, or a kind of nothingness? If so, how can holes exist? A parsimonious ontologist may deny that holes should be included in our ontological catalogue: out there in the world, there 
really are no holes. But then we have a problem: 'There are holes in pieces of Emmental cheese' is a truth of common sense, and for this truth to be true there must be holes in pieces of Emmental cheese - thus, there must be holes.

How about our seventh item - numbers, like $1.08 \cdot 10^{12}$ ? These also look very different from concrete material objects. Saturn has a very large mass - so large that it generates a gravitational field, which would attract you, should you get close enough. In fact, the number $1.08 \cdot 10^{12}$ is, so to speak, too light and thin to have any attractive force on you. It doesn't even make much sense to wonder about the thinness of a number, as well as about its spatiotemporal location. Indeed, $1.08 \cdot 10^{12}$ does nothing physical to you: it is causally inert, as we may say.

But how can we know anything about things we cannot entertain causal relationships with? Can we even be sure that they are there? Even if we were freed from our contingent spatiotemporal limitations, we could never cross paths with $1.08 \cdot 10^{12}$, for it's nowhere to be found in the physical world. Some may find 1.08 . $10^{12}$ and its peers to be too obnoxious to be admitted in our ontological list of the components of the world. Numbers, sets and other mathematical entities must simply not be included in our ontology, these parsimonious folks may claim. On the other hand, refusing to include numbers in our ontological catalogue may also bring problems. If there are no numbers, how could it be true that, as mathematics teaches us, seven is a prime number? This can only be the case, as it seems, if there is a number (seven), which has the feature of being prime - thus, if there are numbers.

How about properties, such as fragility or ripeness, and biological species, such as spiders and insects - our candidate items no. 8 and no. 9? Considerations of ontological parsimony may lead some not to include them in the catalogue either. Of course there are material objects, some of which are ripe or fragile, some of which are human beings. Yet, why should we admit fragility, ripeness or the species homo sapiens, above and beyond the things which are fragile, ripe or human? Parsimonious ontologists might have arguments similar to the ones against numbers (properties and species are often grouped with mathematical objects under the broad label of abstract objects, which we also used above, and opposed to concrete material beings). We see, touch and interact causally with human beings, fragile glasses and ripe bananas, but nobody has ever seen or touched fragility, ripeness or humanity. One may object. We also directly speak of species: we claim that some of them are crossfertile; and this can only be true if there are cross-fertile species, thus, if there are species. We also seem to know things about properties - for instance, we know that fragility is a property of crystal glasses; and this demands that there be properties.

How about item 10 in the list? Events - things that happen - make for another popular ontological category. Events seem ubiquitous in our daily life: Clinton's affair with Lewinsky was scandalous, but Kennedy's killing by Oswald was tragic; the French revolution was a momentous event, while Francesco's watering his flowers yesterday just passed unnoticed. And unlike abstract objects, we cannot easily dismiss 
events on the ground of their being devoid of causal powers. On the contrary, they seem to be the main actors of causal processes: we say that the throwing of a stone caused the breaking of the window, that the Clinton-Lewinsky affair caused the impeachment of the President, and that the latest solar flare caused the emission of billions of joules of energy in the Solar System. Events also present problems of their own, for instance, concerning the fine-grainedness of their individuation. Francesco walks to the same office every working day; but is the event of Francesco's walking to his office one single general event, which recurs many times across the year? Or are we talking of similar but distinct particular events, each with its own unique spatiotemporal setting? We may also have issues with the identity of the particular events themselves: is Oswald's shooting the same as Kennedy's killing?

Now notice that all of these concerns are not typical of disciplines like physics, mathematics or biology. Mathematicians talk about prime numbers; biologists talk about cross-fertile biological species; astrophysicists deal with solar flares. But, qua scientists, they will not typically wonder whether there really are prime numbers, species, properties or events - whether these things ought to be included in the ontological catalogue. Nor will they wonder what it means to ask whether the world really includes these entities or not. Nor will they typically wonder what they themselves are ontologically involved with when they claim that there are infinitely many prime numbers, or that genetic features are shared between spiders and insects.

Nor is common sense unqualifiedly helpful in all of these issues - even though, as we will see throughout this book, some ontologists take the deliverances of common sense, for example, as they show up in our ordinary talk, very seriously. Common sense often delivers vague, imprecise, ungrounded or occasionally inconsistent verdicts on the existence of various kinds of things. Here's one example. It is commonsensical to maintain that everyday objects have parts that constitute them. Bananas have a peel and a pulp, normally endowed human beings have arms, legs and a head. Also, according to common sense, scattered material objects may constitute further objects. A slip and a bra for instance, can compose a further thing: a bikini. Yet it is not commonsensical to think that this can always happen: intuitively, there's no object made up of Brad Pitt's face and George Clooney's body. So according to common sense, two objects sometimes compose a further one and sometimes do not. And there seems to be no commonsensical criterion to draw a principled line between the case in which bunches of material objects compose a further object as its parts, and the case in which they don't. But we need such a criterion to build a well-motivated ontological catalogue.

Here philosophy steps in again. As we will see in the third part of our book, specifically in Chapter 12, philosophical considerations may lead ontology to sharply depart from common sense on the question: 'When does the inclusion of two material objects in our inventory force us to include also one further object, composed exactly of them?'. A parsimonious ontologist may plainly deny the existence of bikinis by 
claiming that what actually exists are just slips and bras. A bikini is nothing but a slip plus a bra: once we have counted the slip and a bra, there is no reason to countenance a further object, the bikini. But then, an even more parsimonious ontologist may claim, slips and bras are nothing but bunches of atoms and molecules arranged in a certain way. Once we have countenanced the (properly arranged) atoms and molecules, there is no reason to further countenance slips and bras. Worse: countenancing them may bring lots of troubles concerning their persistence across time and change and their spatial boundaries. It's better to say that there really are no such things (we now see that, although ontologists look for the most general kinds of being, this does not prevent them from expressing their disagreements more concretely: 'Unlike van Inwagen, I include bananas in my ontology' - not just subatomic particles arranged banana-wise: van Inwagen 2001: 3).

There seems to be room for philosophical work, then - at least, if we are sensitive to issues like the ones just explored, for which physics and the special sciences, but also commonsensical shared beliefs, often deliver no clear verdicts. We may want to know whether apparently problematic entities like numbers, holes and properties can be admitted in our catalogue of the furniture of the world. If we don't include them, we need to make sense of facts, truths and bits of knowledge apparently involving them. If we do include them, we need to answer objections of various kinds to their ontological respectability.

\section{The rest of the book}

The book is neatly divided into two halves. Parts 1 and 2, making for the first half, focus on metaontology. There is a mainstream metaontological view among analytic philosophers: this is dealt with in Part 1. Its origins are traced back to Russell's On Denoting (Chapter 1), which provided the methodological paradigm of philosophical analysis for much of twentieth-century philosophy.

The mainstream view, though, is usually labelled as 'Quinean', for it is most clearly stated in such famous Quinean papers as On What There Is. Chapter 2 explains the pivotal theses of Quine's metaontology: that ontology's key question is: 'What is there?'; that in some sense the question can be answered in one word, 'Everything, for it is trivially true that everything exists, but in another sense it is not trivial at all; that it is inconsistent to make certain claims while holding that things of a certain kind do not exist (what is known as Quine's 'criterion of ontological commitment'); that there is a principled way to settle debates about the existence of things like numbers, propositions, properties, etc.

Chapter 3 delves into the details of the standard metaontological view, as developed, for example, in Peter van Inwagen's essays: being is not a (non-trivial) 
feature of things; being just is existence; being or existence is univocal - it means only one thing; the single sense of being is completely captured by the existential quantifier of elementary logic. It also deals with 'paraphrase strategies' to get rid of ontological commitments apparently brought about by our everyday quantification over unwelcome kinds of things, and with the ontological import of so-called identity criteria, recaptured by Quine's motto 'No entity without identity'.

The consensus about these matters is not universal. On the contrary, much toplevel contemporary work in metaontology starts by calling into question the standard view. Part 2 of the book explores reasons of dissatisfaction with it, and a range of alternative options. Here, Chapter 4 discusses two ways to depart from Quine's framework. The first, that of ontological pluralists, agrees with Quine and van Inwagen that existence or being is captured by the quantifier, but holds that there is more than one mode or way of being, thus there is more than one (primitive) quantifier. Chairs and numbers, according to this view, both exist, but in two very different ways, and a correct description of the world should take this into account. Neo-Fregeans, on the other hand, think that linguistic categories, like that of singular term, are in some sense conceptually prior to ontological ones like that of object. This leads to a view of the relationships between language and reality (broadly linked to the so-called 'linguistic turn' of twentieth-century philosophy) with surprising results for the issue of the existence of abstract objects like numbers and directions.

Chapter 5 focuses on the view of ontology held by Quine's master, Rudolf Carnap, and on its legacy for contemporary ontology. Carnap believed that it makes sense to ask about what there is only on the background of some conceptual and linguistic framework. Assuming the framework of material things, for instance, it makes sense to ask whether there is a skyscraper higher than the Empire State Building, as people ordinarily do. But to ask, as philosophers have traditionally done, whether there are material things in some 'absolute' sense is to ask a very different question. Carnap called questions of the first kind internal and questions of the second kind external. This distinction, together with a certain deflationary attitude towards ontology associated with it, has been a source of inspiration for an amount of recent work in metaontology, ranging from the so-called 'quantifier variance' view to proposals to the effect that we must distinguish an internal and an external reading of quantificational expressions.

Chapter 6 introduces the burgeoning fictionalist strategies, according to which when we make claims that seem to commit us to the existence of controversial entities like numbers, possible worlds, properties, etc., we should not be taken at face value. The fictionalist motto has it that such claims can be 'good without being true', and much work in this area consists in making this motto plausible. However, we speak of fictionalist strategies, in the plural, for we will see in this chapter that fictionalism has been developed in quite different ways by its supporters.

Chapter 7 speaks of (neo-)Meinongian theories taking seriously the view that some things just do not exist (the name comes from Alexius Meinong, an Austrian 
philosopher who held this view).(Neo-)Meinongians are unified by their disentangling the quantifiers from (automatic) existential commitment, but their views are otherwise diversified, too. In particular, they have different non-quantificational conceptions of the meaning of being as well as different proposals on which nonexistent objects there are, and on which properties and features they can display.

Chapter 8 explores recent work on the notion of grounding and its impact on the methodology of ontology. Advocates of the grounding approach tend to see reality as an ontologically hierarchical structure. They hold that the most important question about things of a given kind is not whether they exist, taken in the Quinean sense as a quantificational question. Rather, the most important explanatory task for ontology has to do with which position such things occupy in the structure. Are they fundamental entities, or do they depend for their existence on entities of another kind, and if so, which kind?

Having investigated the issues of the meaning(s) of being and of the methodology of ontological inquiry, in Part 3 of the book, which occupies its second half in length, we give a closer look at how ontological investigations are actually carried out. Here, Chapters 9 and 10 are dedicated to abstract objects of different kinds. Do objects like the number eighteen or Pythagoras' theorem really exist? And what about moral obligations: is there really something like a duty to keep your promise? On the one hand, abstract objects look peculiar: we cannot see, touch or smell them. They are apparently nowhere to be found in the material world surrounding us. On the other hand, is it really possible to renounce abstract objects like numbers and sets without renouncing mathematics? We will extensively review, in particular, the pros and cons of both nominalist positions, which try to make sense of mathematics without admitting abstract objects, and of platonist positions, which admit such objects and try to explain how knowledge of them is possible at all.

Is the actual world we are living in the only one there is? Talk of alternative ways the world could be or have been, also known as possible worlds, is ubiquitous in analytical philosophy, for the notion is extremely helpful to analyse a number of key philosophical concepts. Since David Lewis called our attention to the ontological and metaphysical status of these entities, the debate on them has been lively. Lewis proposed to take possible worlds as (largely) concrete universes, causally and spatiotemporally isolated from each other, but of the same kind as the world we are living in. The view was met with 'incredulous stares'; the literature provides a variety of arguments pro and, more often, against 'Lewisian modal realism'. A survey of this debate, provided in Chapter 11, is a must for an introduction to ontology. The debate on modal realism has been traditionally conducted within a standard largely Quinean metaontological framework. However, we will see in this chapter that nonstandard metaontological views can provide fresh spin-offs to the discussion.

Another peculiar aspect of ontological debates emerges when one realizes that, as already hinted above in this Introduction, for prominent philosophers like Peter van Inwagen there are no such things as mid-size concrete, material objects like a banana 
or a table, but just subatomic particles arranged as so. According to other prominent philosophers, like David Lewis, there are such weird entities as the 'mereological fusion' (from the Greek méros, 'part') of one's head and one's father's body, i.e. that scattered thing whose parts are exactly one's head and one's father's body. For Lewis, given any two entities $x$ and $y$, there always is a (possibly scattered) entity $x+y$, containing exactly them as parts. These views will be described in Chapter 12, devoted to the ontology and metaphysics of material objects. Other topics examined in that chapter include the issue of synchronic identity conditions for such objects (e.g., can more than one of them occupy one and the same place at the same time?) and the one of their diachronic identity (under which conditions do they persist in time in spite of their undergoing change?).

Yet another topic in modern ontologists' agenda has to do with the status of fictional entities: things referred to and described in works of fiction, like Sherlock Holmes, Anna Karenina or Gandalf. Chapter 13 is dedicated to them: we will see there how, while (neo-)Meinongians declare such things to be non-existent, and fictionalists apply to discourse on them their non-ontologically-committing techniques, realist abstractionists on such objects accept that they really exist, but treat them as metaphysically peculiar abstract objects.

Finally, Chapter 14 presents two challenges to the view that the world is nothing but a collection of particular things like this chair, this table, this apple and so forth. It seems that things share features, which make for their similarities. Two red apples are similar in virtue of sharing the feature of being red. Moreover, the world we live in is not boring and static: lots of things happen in it. New persons are born, philosophers debate about ontology, people go to parties. Does not this suffice to show that we should also include in our ontological catalogue properties, like the property of being red or that of being an apple, and events, like births, debates and parties? If so, what are these things? Some philosophers take both kinds of things as universals, that is, as things irreducible to particulars like individual apples and chairs, while others disagree.

The agenda does not end here. Other entries considered by ontologists include works of art, or social objects (things like mortgages, institutions and money), just to mention a few items. Surely, then, this survey of ours is not complete. As Bertrand Russell said at the end of his Introduction to Mathematical Philosophy (Russell 1919): 'there are innumerable unresolved problems in the subject, and much work needs to be done. If any student is led into a serious study ... by this little book, it will serve the chief purpose for which it has been written.' 